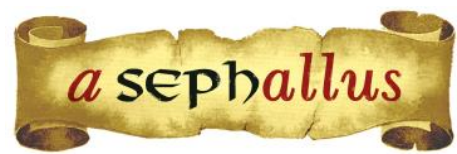

Revista aSEPHallus de Orientação Lacaniana

Núcleo Sephora de Pesquisa sobre o Moderno e o Contemporâneo

ISSN $1809-709$ X

\title{
Os adolescentes, as escolas e os impasses: um recorte da clínica no Janela da Escuta ${ }^{1}$
}

\author{
Ana Lydia Bezerra Santiago \\ Orcid: https://orcid.org/0000-0003-4405-6244 \\ Doutora em Psicologia Clínica pela Universidade de São Paulo/USP (São Paulo, Brasil) \\ Professora associada da Universidade Federal de Minas Gerais/UFMG (Minas Gerais, Brasil) \\ E-mail: analydia.ebp@gmail.com
}

Cristiane de Freitas Cunha Grillo

Orcid: https://orcid.org/0000-0003-2216-7904

Doutora em Saúde da Criança e do Adolescente pela Universidade Federal de Minas Gerais/UFMG (Minas

Gerais, Brasil)

Professora residente da Instituto de Estudos Avançados Transdisciplinares (IEAT) da Universidade Federal de Minas Gerais /UFMG (Minas Gerais, Brasil)

E-mail: cristianedefreitascunha@gmail.com

Izabela de Freitas Cunha Lins Albuquerque ${ }^{2}$

Orcid: https://orcid.org/ 0000-0001-5186-0543

Mestre em Promoção da Saúde e Prevenção da Violência pela Faculdade de Medicina da Universidade Federal de Minas Gerais/UFMG (Minas Gerais, Brasil) Psicóloga pela Pontifícia Universidade Católica de Minas Gerais/PUC-MG (Minas Gerais, Brasil) E-mail: izabelagfclins@gmail.com

\begin{abstract}
Resumo: Trata-se de um estudo sobre a construção interdisciplinar de casos clínicos de adolescentes atendidos no Janela da Escuta, projeto de extensão da Faculdade de Medicina da Universidade Federal de Minas Gerais (UFMG), encaminhados com queixas escolares. Pretendeu-se verificar os impasses gerados pelas demandas de encaminhamento dos adolescentes da escola para a saúde, o papel do atendimento a essas demandas e a postura dos adolescentes diante da experiência, fazendo um recorte da clínica do Janela da Escuta a partir da análise de dois casos. A metodologia utilizada no projeto se baseia na construção do caso clínico pela equipe interdisciplinar, além das conversações de orientação psicanalítica com os profissionais das escolas. Ao final, constatou-se a necessidade e a importância de se ofertar a esses adolescentes um espaço de escuta de suas verdadeiras demandas, onde, por meio do convite à fala, puderam se assumir como protagonistas de suas questões e se reposicionar frente à situação em que se encontravam, tornando possível o aparecimento de sua singularidade.
\end{abstract}

Palavras chave: Adolescência; Psicanálise; Educação; Impasses escolares

Adolescents, écoles et impasses: un extrait de la clinique dans le cadre du projet « Janela da Escuta » (fenêtre d'écoute) : Il s'agit d'une étude sur la construction interdisciplinaire de cas cliniques d'adolescents avec des problèmes scolaires reçus à Janela da Escuta, un projet d'extension de la Faculté de médecine de I'Université fédérale de Minas Gerais (UFMG). L'objectif de cette étude était de vérifier les impasses générées par les demandes d' envoi des adolescents de l'école aux services de santé, le rôle de celui-ci face à ces exigences et l'attitude des adolescents dans cette situation, en présentant un extrait de la clinique de Janela da Escuta en partant de I'analyse de deux cas. La méthode utilisée dans Janela da Escuta est basée sur la construction du cas clinique par l'équipe interdisciplinaire, et dans les conversations d'orientation psychanalytique avec les professionnels de l'école. En fin de compte, la nécessité et l'importance d'offrir à ces adolescents un espace pour écouter leurs vraies demandes, ont été vérifiées. L' invitation à parler leur permet de assumer le rôle principal dans la résolution de leurs questions et de changer de position face à la situation dans laquelle ils sont, rendant possible l'apparition de leur singularité.

Mots clés: Adolescence; La psychanalyse; I'éducation; Impasses scolaires 
Adolescents, schools and impasses: a clipping from the clinic in project "Janela da Escuta": This is a study on the interdisciplinary construction of clinical cases of adolescents referred with school complaints seen at Janela da Escuta, an extension project of the Medical school of the Federal University of Minas Gerais (UFMG). Its purpose is to verify the impasses generated by the demands of referral of adolescents from school to the health services, the role of the project in facing these demands and the attitude of adolescents in this situation, by presenting an excerpt out of the Clinic of Janela da Escuta from the analysis of two cases. The methodology used in janela da Escuta is based on the construction of the clinical case by the interdisciplinary team, in addition to the psychoanalytic orientation conversations with the professionals of the schools. In the end, the need and importance of offering these adolescents a space to listen to their true demands was verified, and in this space, through the invitation to speak, they could assume themselves as protagonists of their questions and reposition themselves in the face of the situation in which they were, enabling the appearance of their singularity.

Keywords: Adolescence; Psychoanalysis; Education; School impasses 


\section{Os adolescentes, as escolas e os impasses: um recorte da clínica no Janela da Escuta}

Ana Lydia Bezerra Santiago \& Cristiane de Freitas Cunha Grillo \& Izabela de Freitas Cunha Lins

\section{Albuquerque}

A escola é reconhecida pela sociedade pelo seu importante papel de formar crianças e adolescentes. Mas quando uma lógica de homogeneização prevalece e se espera que todos os alunos cumpram igualmente as normas estabelecidas pela instituição e assimilem da mesma maneira os conteúdos pedagógicos, surgem os impasses escolares. Quando se esgotam as estratégias para lidar com essas questões dentro da escola, outros saberes são convocados, como a medicina e a psicologia.

Inicialmente, medicina e psicologia se aproximam da instituição escolar por razões higienistas, em virtude da necessidade de fundamentar cientificamente teorias e práticas pedagógicas e de organizar um sistema escolar que incluísse as crianças consideradas anormais ou excepcionais. Com isso, classificações psicológicas e diagnósticos médicos começaram a circular pelas escolas, promovendo ações que organizavam os alunos segundo categorias. Desde a sua formação, a escola teve de lidar com crianças e adolescentes que demonstravam algum impasse na aprendizagem e/ou apresentavam comportamentos considerados pouco adaptados ao contexto educacional (Santiago \& Assis, 2015).

Segundo Santiago (2005), a partir do século XX, surge uma preocupação interdisciplinar em relação ao enfrentamento dos problemas relacionados à educação. Profissionais e especialistas começaram a pensar nas dificuldades apresentadas pelos alunos e em formas de superá-las, tais como estratégias preventivas, práticas institucionais e projetos de ensino. Observa-se a psicologização do fracasso escolar, isto é, o "fracasso" na aprendizagem é atribuído a fatores psicológicos e as questões individuais do aluno, desconsiderando as relações sociais e as políticas que permeiam a instituição escolar (Santiago, 2005).

A psicanálise, no campo da educação, teria o desafio de fazer a singularidade se inscrever no espaço institucional. No meio de um ambiente regido por normas e regras, os psicanalistas privilegiam o real dos sintomas, desconcertando esse ambiente de práticas consolidadas para incluírem, de outra forma, o irreconciliável do que perturba, pois este constitui o mais singular de cada sujeito (Santiago \& Assis, 2015).

As intervenções dos psicanalistas norteadas à desconstrução de nomeações desse Outro escolar, como a dislexia, o transtorno global do desenvolvimento, o transtorno de déficit de atenção e hiperatividade (TDAH), que muitas vezes levam a encaminhamentos para a saúde, inscrevem-se no ponto em que uma falha do saber interroga fenômenos associados ao fracasso escolar. Assim, o desafio do analista é mobilizar essas identificações a fim de promover uma possível reconciliação do sujeito com o que the é singular e que pode ser segregado pelas nomeações. 
Com isso, o psicanalista considera os possíveis impasses do sujeito com relação ao saber, mas também há de considerar os sintomas produzidos em cada escola, pois esta também pode ser vista como um sujeito que gera situações contrárias àquilo a que se propõe como instituição educativa. Desse modo, o fracasso escolar pode ser visto como uma dessas manifestações indesejadas do sujeito-instituição, sendo sintoma, portanto, da escola, que é incompatível com o seu objetivo de ensino da leitura e da escrita. Como sintoma da instituição, o fracasso em alfabetizar alunos e em fazê-los seguir as normas da escola cria um mal-estar que se repercute sobre vários atores da escola e do processo de educação (Santiago, 2005).

\section{Janela da Escuta}

Diante deste cenário, este trabalho pretende verificar os impasses entre as demandas de encaminhamento dos adolescentes da escola para a saúde, o papel desta frente a essas demandas e as questões dos próprios adolescentes. A pesquisa toma o ambulatório Janela da Escuta como cenário e investiga, na perspectiva da psicanálise, casos de impasses escolares, além de promover uma discussão interdisciplinar sobre as relações entre problemas escolares e intervenção em saúde por meio da metodologia de Conversação de Orientação Psicanalítica, realizada em conjunto com uma equipe interdisciplinar que conta com médicos, artistas, assistentes sociais, terapeutas ocupacionais e psicólogos.

A partir das discussões de casos clínicos do Janela da Escuta relacionados à demanda da educação, foram levantadas algumas questões sobre os adolescentes considerados alunosproblemas, sobre as intervenções tanto clínicas, quanto escolares e familiares que eles recebiam, e sobre sua relação com essa demanda. Essas questões podem ser sintetizadas nas seguintes perguntas: o que o adolescente realmente sabia? O que ele sabia sobre essa demanda? 0 que ele sabia sobre os conteúdos escolares? O que essa demanda da escola tinha a ver com ele? Qual era o seu interesse? Afinal, qual o papel da escola para os adolescentes? E por que os adolescentes foram encaminhados a um serviço de saúde?

A partir da experiência no Janela da Escuta, verificou-se que o encaminhamento de adolescentes aos serviços de saúde para diagnóstico e acompanhamento em razão de sua dificuldade de aprendizagem introduz um desafio para os profissionais da área da saúde, sobretudo na demarcação do diagnóstico e na investigação da causalidade, orgânica ou psíquica; para os familiares e profissionais da escola, principalmente quando a hipótese que eles tinham sobre o aluno não é confirmada pelos profissionais de saúde; e até mesmo para o adolescente, que muitas vezes não é questionado sobre a nomeação que recebe.

As reuniões clínicas do Janela da Escuta, nas quais se trabalha a construção de cada caso pela equipe interdisciplinar, permitiram a escolha de alguns casos para o estudo. A pesquisadora participou dessas reuniões, entrevistou os adolescentes e os familiares e realizou conversações com os profissionais das escolas. A aposta da conversação é passar da queixa - que paralisa a 
ação dos profissionais da escola, e produz identificações indesejáveis para os pacientes e alunos a um outro uso da palavra, em que a queixa toma a forma de uma questão, e a questão, a forma de uma resposta: invenções inéditas (Santiago, 2011).

Em cada caso, buscou-se depurar as demandas das escolas, o discurso dos familiares e o discurso dos adolescentes.

\section{A pesquisa}

\section{Caso Theo - A demanda ao Janela da Escuta}

Theo, 14 anos de idade, estava repetindo o sexto ano pela terceira vez em uma escola pública de Belo Horizonte. Ele chegou ao Janela da Escuta devido à demanda dos pais, que, no acolhimento, disseram que o filho era muito levado na escola e em casa.

\section{Discurso da família}

Os pais buscaram o atendimento por causa das queixas da escola sobre o comportamento indisciplinar de Theo, e porque o filho apresentava baixo rendimento nas disciplinas. Os pais eram muito invasivos em relação aos atendimentos de Theo: frequentemente requisitavam uma conversa, que era sempre realizada na presença do adolescente. As demandas que os pais apresentavam sobre Theo giravam em torno das queixas escolares, das brigas entre mãe e filho e da advertência judicial que sofreu por ter praticado um ato infracional.

A família era constituída pelo pai, que trabalhava em dias alternados; pela mãe, que havia deixado seu trabalho formal para cuidar dos filhos; por Theo e por seu irmão mais velho, que havia abandonado a escola e se tornado pai, ainda adolescente.

A mãe foi acolhida por uma psicóloga do Janela da Escuta, mas depois recusou esse atendimento. Sempre falava sobre o histórico escolar de Theo e sobre suas tentativas de colocar o filho no caminho que acreditava ser melhor, afirmando que Theo só sabia fazer o pior e que ele seguiria o caminho dos tios maternos, que foram criminosos e acabaram assassinados.

Mãe e pai identificavam no filho alguma habilidade, reconheciam que ele era bom em reproduzir armas de madeira ou em fazer um dispositivo que aprendeu na internet para provocar um curto-circuito na escola. Porém, afirmavam: "estamos cansados, não sabemos mais o que fazer com ele."; "ele só aprende coisa errada, as coisas de escola ele não aprende"; "queremos uma consulta com o psiquiatra, só pode ser algum problema de cabeça".

\section{O acompanhamento de saúde}

O acompanhamento de saúde do adolescente no Janela da Escuta iniciou-se na pediatria, mas se estendeu para a psicologia. Em equipe, os profissionais do Janela da Escuta debateram sobre a demanda desenfreada dos pais por uma consulta psiquiátrica para o filho e concluíram que seria melhor que ele fosse atendido por alguém da equipe do que por algum outro profissional, 
encontrado pelos pais, que poderia não ter a mesma sensibilidade de perceber a complexidade e a singularidade que o caso de Theo exigia. Theo concordou com essa avaliação.

Com a psiquiatra, Theo, pela primeira vez, falou do ato infracional que cometera. Durante a consulta, aparentemente, ele percebeu que às vezes age sem pensar e que isso poderia prejudicálo, e concordou com a sugestão de ser medicado para conter sua impulsividade. Quando questionado pela médica sobre três desejos que gostaria de realizar, expressou bem sua adolescência: desejava um celular - para entrar na internet, para estar conectado, por dentro de tudo; em segundo lugar, queria que a mãe o deixasse ir para a rua - para o lugar que the pertence, onde pode ser ele mesmo; por fim, gostaria que o pai liberasse sua bicicleta - para ter sua liberdade.

\section{Discurso da escola}

Em uma conversação na escola de Theo, na qual estavam presentes a diretora e a supervisora, elas falaram que o adolescente tinha o hábito de furtar coisas na escola e fora dela. Elas falaram de uma negligência dos pais em relação ao filho, a diretora pontuou que nunca havia visto um ato de amor por parte da mãe dele, que o chamava de bandido. Além disso, quando era chamada por causa de algum ato indisciplinar do filho, ela colocava a culpa nos amigos dele.

Tanto a diretora quanto a supervisora pontuaram que, com base na experiência que tiveram com outros alunos parecidos com Theo, acreditavam que ele necessitava de um remédio para conter sua impulsividade. Segundo elas, ele não apresentava limites nem noção do perigo. Ainda disseram que ele havia sido matriculado há três anos, tendo repetido um ano por abandono das aulas, outro, por não parar em sala de aula, e que, agora, seria retido novamente por não fazer as atividades. Alegaram também que, antes, era mais difícil mantê-lo dentro de sala de aula, e que, nesse ano, estavam conseguindo mantê-lo até a hora do recreio.

Ao final, as educadoras perceberam que o motivo do comportamento inadequado de Theo é a sua vulnerabilidade social, além da falta de estrutura familiar, e disseram temer pelo seu futuro, por acreditarem que ele já estaria no mundo do crime.

\section{Discurso do adolescente}

Nas primeiras entrevistas, Theo se mostrava como a pediatra o descrevera: desinteressado, monossilábico e apático. 0 adolescente, apesar dessa postura diante dos profissionais de saúde, estava sempre com um sorriso no rosto, dizia que estava tudo bem, e somente falava que "minha mãe é muito chata". Em geral, contava sobre suas saídas para a rua, das brincadeiras com os amigos na quadra do prédio, dos papagaios que gostava de soltar e das brigas com a mãe por não aceitar suas saídas.

Durante o acompanhamento no Janela da Escuta, houve uma mudança na postura do adolescente: estava mais ativo e participava mais do Arte na espera. Ele passou a contar sobre o 
namoro, a falar da percussão e de seu comportamento na escola. Também descrevia a atividade de confecção de armas de madeira em casa, e as brincadeiras de gangues com os colegas, nas quais Theo era o único que sabia fazer dinheiro, sendo para isso demandado. Por outro lado, também relatava como sempre era flagrado na escola e seus pais acionados pela diretora.

Em seu discurso sobre as questões da escola, mostrava-se sempre muito apático e justificava-se, sempre se isentando de responsabilidade, afirmando que era sua mãe quem precisava de tratamento. Dizia "não passei no ano passado porque minha mãe não me deixou fazer a recuperação, mas esse ano é só eu fazer os trabalhos de recuperação que eu passo", e, apesar de sua postura de recusa, era possível perceber também um vínculo com a escola e com os professores de geografia e matemática.

Depois de uma fuga de casa, disse: "Não posso fazer nada em casa. Qualquer coisa que faço minha mãe reclama com o meu pai, que me bate."

Após o recesso de fim de ano, o tratamento foi interrompido pelos pais.

\section{Discussão do caso}

Ao longo do acompanhamento, foi trabalhada com Theo a sua posição diante das questões de sua família, tendo em vista que, para ele, as posições familiares pareciam já rígidas, que sua mãe é quem não o deixa fazer nada, e que seu pai acolhe as demandas da mãe e o agride por isso.

O trabalho com Theo estava caminhando na construção de sua resposta singular, na tentativa de que ele se desvinculasse do discurso dos pais e da escola, mas essa construção era permeada pelas condutas de risco. Mas, quando ele começou a se posicionar frente às suas questões, os pais interromperam o acompanhamento. Em relação à escola, foi possível perceber que há um descrédito por parte de Theo, mas, por outro lado, verifica-se que a instituição de ensino tem uma função para ele, talvez a de oferecer um espaço onde, na companhia de seus colegas e professores, ele possa produzir algo, assim como acontece na rua, em suas saídas. Diante dessas questões, é importante lembrarmos o que envolve a adolescência. Lacadée (2011) sustenta que o púbere percebe as modificações de seu corpo como sendo outro corpo, como se sua terna despreocupação da infância estivesse sendo arrebentada, de maneira real, e percebe que os significantes ideais do Outro parental são subvertidos. Dessa forma, ele é tomado pela estranheza nessa metamorfose de seu corpo, deparando-se com algo que não consegue traduzir na língua do Outro e se confronta com um impasse, com o sentimento de vazio matizado de vergonha. E essa vergonha pode levá-lo ao desgosto, ao ódio de si mesmo, ao ódio dessa vivência da puberdade (Lacadée, 2011).

Uma maneira de o adolescente lidar com esse vazio seria se desviando das leis, que até então eram regidas de modo conformado e inventando novos parceiros, podendo, até mesmo, colocar sua vida em risco: o que parece acontecer com Theo no caminho em que começou a 
flertar com a delinquência. A questão é saber qual preço o adolescente terá que pagar para ultrapassar essa etapa de encontro com o desejo sexual, de remanejamento da vida sexual infantil e da escolha de objeto de amor.

O adolescente deve, então, inventar sua própria abertura significante em direção à sociedade, de modo que ele não se veja mais como criança aprisionada no desejo do Outro, ou seja, de modo que ele possa perceber sua maneira de ver o mundo e de se ver no mundo. Assim, afirma Lacadée (2011), um paradigma da busca de todo adolescente é quando ele começa a questionar e mesmo a denunciar a língua cujos semblantes o sustentaram até então, chegando até mesmo a inventar uma nova língua. Por isso, parece que há algo chamando-o para fora de sua casa, pois somente lá se encontra a vida verdadeira, o que ele crê ser o mundo real que o conduz a rejeitar os semblantes do Outro que até então o velam (Lacadée, 2011).

E "encontrar uma língua", segundo Lacadée (2011), permite "tomar uma posição", ainda que de forma desrespeitosa e incômoda para o Outro. Essa é, frequentemente, a solução do impasse, adotada pelos adolescentes. Por isso, é importante oferecer ao adolescente o espaço de liberdade de fala, oferecendo ao sujeito a via de um novo dizer e, através da conversação, tentar afastar o que poderia devastar o seu ser. A partir de sua singularidade, o adolescente pode ser visto e pode se orientar a partir de uma nova fala, uma nova tomada de posição na língua. "Eis o abrigo que pode oferecer o encontro com um psicanalista, guiando o adolescente na tarefa de bem dizer seu ser" (Lacadée, 2011, p. 23).

Dessa forma, a posição do analista foi ofertar esse espaço próprio de confiança ao sujeito, apostando na potência dele, barrando a demanda desenfreada dos pais, principalmente da mãe, e oferecendo a ela outros espaços, para que ela pudesse trabalhar suas próprias questões. Além disso, foi importante, na conversação realizada na escola, apontar um questionamento em relação ao adolescente para além das questões de vulnerabilidade que o envolve.

A ausência de demanda não pode ser uma forma dos serviços que lidam com os adolescentes de se ausentarem, como se isso servisse como respaldo para encaminhá-lo a outro setor. Por isso, a pediatria acolhe no primeiro momento e, posteriormente, ao oferecer a escuta, a demanda começa a aparecer, mesmo que de forma tímida.

No que tange à postura do educador, Lacadée (2011) afirma que é necessário sentar-se ao lado do adolescente para estabelecer uma relação de confiança e, então, fazer-lhe um convite, uma oferta de tradução e nomeação para o que já foi tomado como delinquência, desvio e errância. E tal empreitada de tradução exige um lugar de acolhida no qual o sujeito possa medir sua própria responsabilidade, a de responder por intermédio de sua própria linguagem (Lacadée, 2011).

Observando-se toda a trama familiar, verifica-se que Theo se constituía como o sintoma do par parental. A mãe se colocava de forma feroz e designava um destino para o filho, o de ser 
criminoso como seus tios maternos, já o pai se apresentava a serviço dessa mãe, em uma posição mais passiva.

Nesse sentido, vale citar o que Lacan (1969/2003) ensina sobre o sintoma da criança se encontrar na situação de responder por aquilo que há de sintoma na estrutura familiar. No contexto da família de Theo, o sintoma se define como representante da verdade do casal. Com isso, é pelo correlato de uma fantasia que a criança está interessada (Lacan, 1969/2003).

A distância entre a identificação com o ideal de ego e a parte presa no desejo da mãe, se ela não tiver mediação (aquela que normalmente a função do pai assegura), deixa a criança aberta a todas as capturas fantasmáticas. Ela se torna o "objeto" da mãe e não tem outra função que a de revelar a verdade desse objeto (Lacan, 1969/2003, p. 369).

Portanto, a criança, segundo Lacan (1969/2003) se apresenta como objeto da fantasia. E, na tentativa de substituir esse objeto, qualquer que seja a estrutura especial de sua mãe, ela satura o modo de falta em que se especifica o desejo da mãe. A criança, então, aliena em si todo o acesso possível da mãe à sua própria verdade, dando-lhe corpo, existência, e mesmo exigência de ser protegida (Lacan, 1969/2003).

Isso foi percebido na interrupção do tratamento de Theo, provocada pelos pais, talvez porque algo tenha sido tocado nesse ponto sintomático da família.

\section{Caso Breno - A demanda ao Janela da Escuta}

Breno, 15 anos de idade, cursava o $9^{\circ}$ ano em uma escola pública de Belo Horizonte, e havia sido transferido de escola devido à sua indisciplina. Ele e sua mãe chegaram ao Janela da Escuta por demanda espontânea. A mãe explicou que soube do acompanhamento de outro adolescente pelo serviço e que achava que seu filho também deveria ser atendido, por causa dos problemas de indisciplina e baixo rendimento escolar. Ainda no acolhimento, Breno também demonstrou um incômodo em relação às suas questões escolares. Após a conversação clínica em equipe, 0 adolescente iniciou, de forma consentida, o acompanhamento com a psicologia.

\section{Discurso da mãe}

Segundo a mãe, Breno tem dificuldade de aprendizagem desde o início da vida escolar, o que Ihe faz suspeitar da existência de algum problema cognitivo. Ela relatou, ainda, sobre uma situação que o filho havia passado com o pai, há dois anos, e que poderia ter contribuído para seu problema escolar. Percebe-se, portanto, que ela flutua em sua opinião sobre o quadro escolar do filho, considerando-o ora como um problema cognitivo, ora como um problema de ordem emocional. 
Quanto ao contexto familiar, é importante pontuar que Breno é fruto de um relacionamento efêmero entre os pais. A mãe relatou que tem uma relação conflituosa com o pai de Breno, que está foragido da polícia por envolvimento com o tráfico de drogas e que, devido às suas condições, pede para ver o filho no mesmo horário da escola, do que ela discorda. Contou, ainda, que, há uns dois anos, enquanto estavam discutindo, o pai falou na frente do Breno que o desinteresse pela escola era de família, que ele também nunca gostou de estudar. Para ela, o filho piorou na escola a partir desse dia. Foi possível notar que a mãe acredita que o discurso do pai tem poder sobre Breno, sobre seu futuro, e teme que ele siga o caminho do pai. Por causa disso, sempre que Breno não vai bem na escola ou faz algo sem sua permissão, ela pune o filho, proibindo que ele visite o pai.

Logo após o acompanhamento de Breno ter sido iniciado no Janela da Escuta, a mãe de Breno, ainda nos corredores do ambulatório, falou que ele estava escondendo, debaixo de seu colchão, o seu boletim e os comprovantes de comparecimento ao serviço, que deveriam ser entregues na escola. Além disso, ela informou que, naquela semana, teve de acompanhá-lo na entrada da escola, por exigência da coordenação, porque Breno havia desacatado o professor de português.

Segundo ela, "o problema de Breno é falta de interesse, pois, quando ele ainda não estava enturmado com os colegas, conseguiu ter notas razoáveis, que pioraram assim que ele se enturmou". Em seu discurso, a mãe coloca que percebe no filho uma falta de estímulo para qualquer tarefa diária, seja esquentar o seu próprio almoço ou ir para o futebol, se o primo se ausenta ou se ele se atrasa para pegar o ônibus. Acha que tudo é muito difícil para Breno. Ao final, ela afirmou que nunca foi feita uma investigação sobre os problemas escolares do filho. Recentemente, a mãe procurou aulas de reforço para o filho, nas quais ele se mostra interessado e ajuda os colegas.

\section{Discurso da escola}

$\mathrm{Na}$ tentativa de entender a posição de Breno na escola, foram realizadas duas conversações. Na primeira, a coordenadora pedagógica pontuou que a mãe tinha sido requisitada devido à indisciplina de Breno, contou que ele não ficava quieto em sala de aula e que só fazia as atividades requeridas quando o professor insistia. Disse, ainda, que ele não seguia as normas da escola. A coordenadora conversou com os professores de Educação Física e de Geografia e ambos disseram que não acreditavam que Breno teria algum déficit cognitivo, e que achavam que o problema dele era preguiça. Porém, nunca chegaram a questioná-lo sobre esses comportamentos.

Em uma segunda conversação na escola, a coordenadora apresentou a pasta do aluno, na qual não havia muitos registros, somente as informações do aluno e o contrato escolar, já que ele começou a estudar nesta escola no ano passado. A coordenadora relatou que, há algumas semanas, Breno chorou muito na escola. Ela o levou até sua sala para conversar e ele contou 
sobre a situação de seu pai e que gostaria de vê-lo, mas que sua mãe não o deixava. Sobre as notas de Breno, ela acreditava que se ele se esforçasse, ele conseguiria acompanhar a turma, disse que seu problema é ser influenciável pelo grupo e o colocou como o "melhorzinho" deles. Já a professora de ciências relatou que tem dúvidas sobre sua competência no aprendizado e que se ele conseguisse passar de ano, graças aos vários projetos na escola, provavelmente ele ficaria retido no ensino médio, e disse que Breno ficava muito no celular durante a aula. Elas foram comunicadas a respeito das aulas de reforço e ambas ficaram surpresas com o fato, pois, para elas, não parecia que ele tinha uma ajuda fora da escola.

\section{Discurso do adolescente}

Breno se apresentava para os atendimentos sempre de forma tranquila, com um sorriso no rosto, mas passava a impressão de que não queria estar ali. Era monossilábico, quase não falava, respondia muito com a cabeça e com o olhar, e demorava a formular algumas pequenas frases.

No primeiro atendimento, foi explicado a Breno sobre o trabalho feito em equipe no Janela da Escuta e junto à sua escola. Ele, então, contou que sempre estudou em outra escola, que lá não aprendia, mas nunca ficou retido, pois lá só se tomava bomba por baixa frequência, e esse ano se mudou por causa de bagunça. Explicou que não fazia as atividades e não ficava quieto. Uma vez, inclusive, mexeu com um guarda municipal que estava na escola e quase foi para o Centro Integrado de Atendimento ao Adolescente - CIA. Contou que sua mãe costumava Ihe colocar de castigo, ficando sem sair para a rua e sem celular.

Sobre a escola, dizia: "matemática e geografia consigo fazer as atividades porque entendo mais, mas ciências, inglês e português não fico quieto"; "não faço as atividades porque não entendo, acho difícil, então prefiro bagunçar"; "eu queria aprender, mas prefiro a bagunça". Sobre o futuro, falou, ainda no primeiro contato, que queria trabalhar. Reconheceu que, para isso, precisa estar estudando e apresentar um bom rendimento escolar, e que seu desejo não estava de acordo com suas atitudes. Ao mesmo tempo, narrou que prefere estar na rua, brincando, a estudar. Contou que gostava de conversar com seus amigos por mensagem no celular e de jogar um jogo de guerra online.

Ao falar sobre as aulas de reforço, Breno parecia um pouco confuso e tinha dificuldade de explicar há quanto tempo teve essas aulas e qual era a sua frequência. Dizia apenas que a aula era em grupo, na casa da professora, e que trabalhava mais as disciplinas de matemática e português.

Ao longo dos atendimentos, Breno começou a falar do seu desejo de morar com o pai, o que só aconteceria se ele requisitasse sua guarda judicialmente, algo extremamente improvável.

Nos últimos atendimentos, porém, Breno tem falado de outras questões, para além do pai. Ele fala sobre seu interesse por uma pessoa que sempre vê na rua e de outras com as quais conversa pelo celular, e afirma que ainda não houve um contato mais íntimo com nenhuma delas. 


\section{Discussão do caso}

Quando essa demanda inicial da mãe cedeu lugar para as construções do adolescente, percebeu-se uma abertura para novas formulações, tornando a queixa escolar menos consistente. o que ele queria era falar de sua bagunça, do que fazia no celular. Seu olho brilhava quando o assunto não era a escola. $E$ isso se tornou possível também pelo fato de entender que cada campo tem de lidar com o que é seu, e que a construção do caso só é possível quando se permite que a singularidade do sujeito apareça.

Em relação à conversação realizada na escola, verificou-se que ela requisita a presença da mãe, por causa dos atos de indisciplina do filho, sem apresentar uma proposta de solução, de algo que de fato possa ser realizado junto ao adolescente e que surta algum efeito. Portanto, a finalidade da requisição parece ser a de se queixar. Além disso, quando o coloca como o "melhorzinho" de sua turma, a escola cria um estigma, uma nomeação.

Tendo como base o caso de Breno, é possível refletir sobre o fenômeno da segregação, tão presente nas instituições escolares, as quais deveriam, no exercício de suas funções, encarnar o direito universal à educação (Santiago, 2005).

$O$ ato do educador é sua transmissão, o resultado desta não é algo previsível ou passível de um ato coletivo, sempre haverá alunos que aprendem e outros que não, o aprendizado é marcado por sérias distorções. Assim, sejam quais forem os métodos pedagógicos utilizados, se se admite a existência do inconsciente, não é possível fixar uma relação de causalidade entre os meios e os efeitos obtidos (Santiago, 2005).

Dessa forma, entre professor e aluno, independentemente dos conteúdos escolares, haverá sempre um intercâmbio de elementos inconscientes que podem ser apreendidos apenas a partir da manifestação de uma desordem qualquer. Assim, o diagnóstico freudiano coloca o fracasso como signo do que não cessa de não se escrever na vida desses sujeitos. E a tarefa do discurso analítico, diante disso, consiste, então, em tentar fazer desse impossível um sintoma, para além das determinações orgânicas ou cognitivas imputadas pelo discurso da ciência como fonte de um déficit do sujeito (Santiago, 2005).

\section{Considerações finais}

Comportamentos estranhos, a não aprendizagem, as falas nem sempre compreendidas, tão presentes na relação ensino/aprendizagem e na transmissão do saber, acabam gerando ansiedade em alguns professores, o que provoca a nomeação. Dessa forma, os educadores nomeiam em virtude da suspeita de transtornos ou síndromes, que parecem tão bem traduzir o que foi captado como diferente no comportamento de certos alunos; ou, ainda, nomeiam quando pressupõem que os alunos não se enquadram em normas escolares ou recusam atividades pedagógicas por causa de suas condições familiares ou sociais, porque estariam sujeitos a algo 
que a própria cultura produz de indesejado no momento atual - violência ou perversão (Santiago \& Assis, 2015).

Em definitivo, trata-se da emergência de um real irreconciliável que convoca uma localização imaginária e uma nomeação simbólica, para aplacar a angústia suscitada por aquilo que não pode ser dominado, no plano pessoal, ou controlado, na relação pedagógica, e que, por isso, ameaça fazer fracassar o plano mais global do ideal civilizatório contemporâneo (Santiago \& Assis, 2015, p. 22).

Nos dois casos, a ênfase da escola recaía na falta de estrutura familiar, que determinaria um presente e um futuro sem chance de mudança e de aprendizagem.

As separações e as novas uniões efetuadas ao longo da vida dos adultos foram formando, aos poucos, um novo tipo de família, que Kehl (2003) chamou de tentacular.

Se um ideal de família nuclear e patriarcal não for superado, pode funcionar como impedimento à legitimação da experiência viva dessas famílias atuais, misturadas, engraçadas, improvisadas e mantidas com afeto, esperança e desilusão, na medida do possível (Kehl, 2003).

Ao colocar o problema do aluno apenas no âmbito social e familiar, cala-se o sujeito em foco, o que prejudica a transmissão dos saberes e afeta o processo escolar, dando corpo a uma hostilidade latente (Santiago \& Assis, 2015).

Em relação às questões familiares, em ambos os casos se percebeu a postura das mães de querer tecer um destino para os filhos. Em conformidade com o que mostrou Lacan (19731974/Inédito), parece que há um projeto da mãe sobre o filho. Ele coloca que "ser nomeado $a$, eis o que coloca uma ordem que efetivamente se substitui ao nome do pai. Com a seguinte ressalva: geralmente basta a mãe para designar o projeto, para fazer o traçado, indicar o caminho [...]." (Lacan, 1973-1974, aula de 13/11/73). Dessa forma, a mãe e o seu desejo, cada uma em cada caso, é que designam para o filho esse projeto que se exprime pelo nomear a. Com isso, os adolescentes ficam impossibilitados de construir uma saída, de produzir algo que lhes seja próprio. E é esse o trabalho que foi proposto em ambos os casos nos tratamentos orientados pela psicanálise.

Em relação às nomeações, Santiago e Assis (2015) apontam a importância do psicanalista na escola, e do seu papel de, através das conversações, desconstruir as nomeações do Outro escolar e inscrever um ponto em que uma falha do saber interroga fenômenos associados ao fracasso escolar (Santiago \& Assis, 2015).

Assim, a função do psicanalista é a de se interpor entre a nomeação e o sujeito, como afirma Miller (2017). A própria adolescência pode se tornar uma nomeação segregativa. Aprendemos com os casos, estes e outros, sobre a potência da adolescência, que sendo um tempo 
de desligamento da autoridade dos pais, pode criar o novo, se não é submergida nos protocolos que visam adaptação e docilidade.

\section{Notas:}

1. Grupo de pesquisa em que o trabalho foi realizado: Subjetividade e cultura do Programa de Pós- graduação em Promoção da Saúde e Prevenção da Violência da Universidade Federal de Minas Gerais (UFMG) e Núcleo Interdisciplinas de Psicanálise e Educação (NIPSE) da Faculdade de Educação da Universidade Federal de Minas Gerais (UFMG).

2. O trabalho foi baseado na dissertação de mestrado Os adolescentes, as escolas e os impasses: um recorte da clínica no Janela da Escuta, defendida em 2019 pela Universidade Federal de Minas Gerais (UFMG).

\section{Referências Bibliográficas}

Kehl, M. R. (2003) Em defesa da família tentacular. In: G. C. Groeninga \& R.C. Pereira, Direito de Família e Psicanálise: rumo a uma nova epistemologia (pp. 163-176). Rio de Janeiro: Imago.

Lacadée, P. (2011). O despertar e o exílio: ensinamentos psicanalíticos da mais delicada das transições, a adolescência. Rio de Janeiro: Contra Capa Livraria.

Lacan, J. (1973-1974). Le Séminaire: Livre XXI: Les non dupes errent. Não publicado.

Lacan, J. (1969). Nota sobre a criança. In: J. Lacan. Outros escritos. (pp. 69-370). Rio de Janeiro: Jorge Zahar, 2003.

Miller, J.-A. (2017). Crianças violentas. Opção Lacaniana, (77).

Santiago, A.L. (2005). A inibição intelectual na psicanálise. Rio de Janeiro: Jorge Zahar Editor.

Santiago, A.L. (2011). Entre a saúde mental e a educação: abordagem clínica e pedagógica de sintomas na escola nomeados por dificuldades de aprendizagem e distúrbios de comportamento. In A. L. Santiago \& R. H. F. Campos (Org.), Educação de crianças e jovens na contemporaneidade. Belo Horizonte: Ed. PUC Minas.

Santiago, A.L. \& Assis, RM. (2015). O que esse menino tem? Sobre alunos que não aprendem e a intervenção da Psicanálise na escola. Belo Horizonte: Ed. Sintoma. 
Citacão/Citation: Lydia Bezerra Santiago, A. \& de Freitas Cunha Grillo, C. \& de Freitas Cunha Lins Albuquerque, I. (mai. 2019 a out. 2019). Os adolescentes, as escolas e os impasses: um recorte da clínica no Janela da Escuta. Revista aSEPHallus de Orientação Lacaniana, 14(28), 91-105. Disponível em www.isepol.com/asephallus. Doi: 10.17852/1809-709x.2019v14n28p91-105

Editor do artigo: Tania Coelho dos Santos.

Recebido/Received: 02/08/2019 / 08/02/2019.

Aceito/Accepted: 04/10/2019 / 10/04/2019.

Copyright: (c) 2019 Associação Núcleo Sephora de Pesquisa sobre o moderno e o contemporâneo. Este é um artigo de livre acesso, que permite uso irrestrito, distribuição e reprodução em qualquer meio, desde que o autor e a fonte sejam citados/This is an open-access article, which permites unrestricted use, distribution, and reproduction in any medium, provided the author and source are credited. 